\title{
Área aberta como conflito entre pedagogia(s) e arquitectura
}

\author{
Miguel Martinho1
}

\section{RESUMO}

Este artigo pretende "explorar" algumas explicações para a falta de sucesso das escolas de área aberta em Portugal. Mais do que contar a história deste tipo de escolas, uma das pretensões foi ilustrar algumas dificuldades e, de algum modo, as razões que conduziram a transformações radicais do espaço físico e pedagógico originalmente proposto para este tipo de organizações educacionais.

Procuramos apontar alguns elementos que contribuíram para esse aparente "fracasso" (falta de estabilidade das equipes docentes, número excessivo de alunos por professor, inexistência de experiências piloto, dentre outros).

As escolas de área aberta foram amplamente contestadas em Portugal. Muitos professores, administradores e até encarregados de educação consideram este modelo de escola inapropriado e por isso um "fracasso". Recentemente, no entanto, a Escola da Ponte, uma das escolas de área aberta que "sobreviveu", foi reconhecida num guia sobre experiências inovadoras. Curiosamente, uma das principais razões do sucesso desta escola, na opinião de elementos da equipa docente, é precisamente o seu design em área aberta.

\section{PALAVRAS CHAVE:}

Escola de área aberta; pedagogia; arquitetura; Escola da Ponte;

\section{Open plan as a "conflict" between pedagogy(ies) and architecture}

\begin{abstract}
This article intends to "explore" some explanations for the lack of success of "open plan schools" in Portugal. More than telling the history of this kind of schools, the pretension was to illustrate the difficulties and, in some way, the reasons that led into the radical transformation of the physical and pedagogical space originally proposed for this educational organizations. The article points out some causes of this apparent failure (lack of stability of the teaching teams, excessive number of students per teacher, inexistence of pilot experiences).

Open plan schools have been largely contested in Portugal. Many teachers, administrators and even parents think that this model of schooling was inappropriate and therefore a "failure". Recently, however, the "Escola da Ponte", one of the open plan schools that "survived", was recognised as one of the country's most innovative educational facilities. Curiously, one of the main reasons for the school's "success", in the opinion of the teaching staff, is precisely the open space design.
\end{abstract}

KEY-WORDS:

Open plan schools; pedagogy; architecture; Escola da Ponte;

1 Actualmente, Miguel Martinho é professor de Música no Ensino Básico e leciona Teoria do Desenvolvimento Curricular no curso de Mestrado em Educação Musical do Instituto Piaget. 


\section{Área aberta como conflito entre pedagogia(s) e arquitectura}

Seguindo uma definição simples, apresentada por HAMILTON (1976: 8), poderíamos considerar uma escola de área aberta como um edifício construído de acordo com um design que não inclui salas de aula "fechadas". Tal como nos diz HAMILTON (1976), uma escola de área aberta, acomodando o mesmo número de alunos, terá menos portas internas e paredes do que uma escola típica "tradicional" com salas de aula. Este design em open space (área aberta) é muito utilizado no mundo empresarial2, mas foi especialmente popular em termos de arquitectura escolar nos anos 1960 e 1970, especialmente nos países escandinavos e nos da América do Norte, embora o conceito se tenha difundido globalmente.

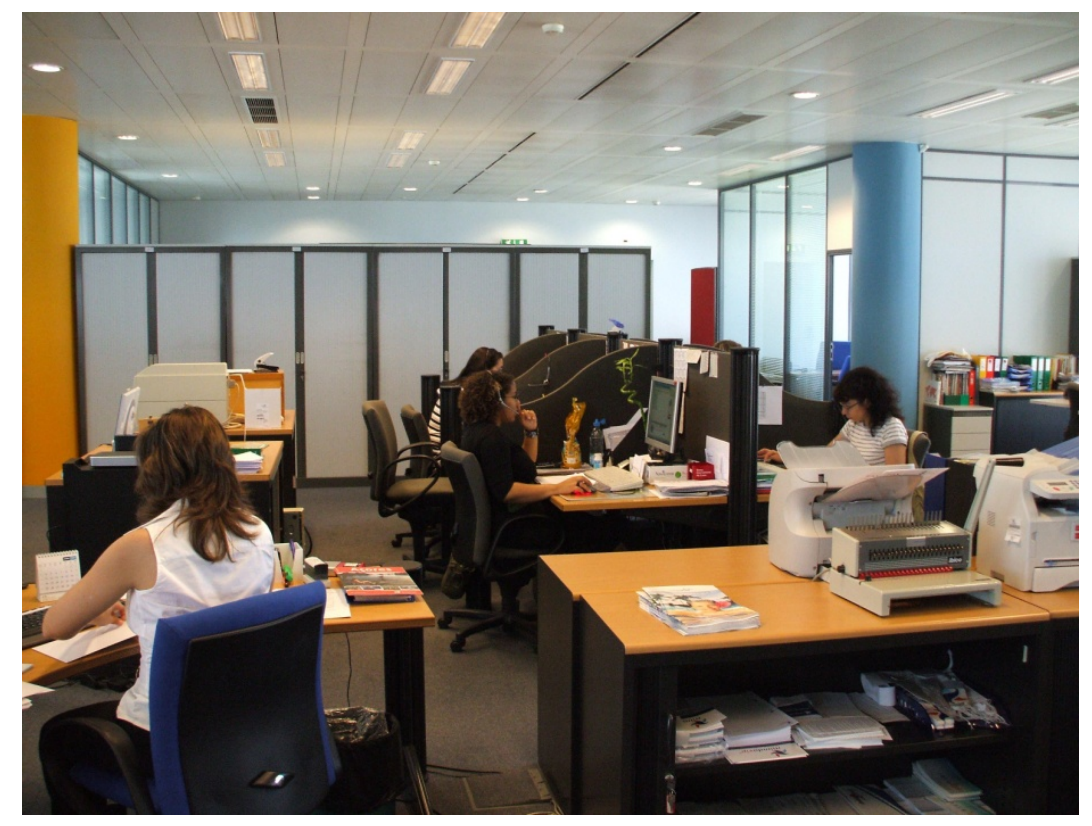

Figura 1 - Ambiente de trabalho em open space

2 Podemos encontrar ambientes de trabalho igualmente em área aberta em "gigantes" da Internet como a Facebook ou a Google. É curioso que nestes dois casos, juntamente com os mais avançados meios tecnológicos, encontramos quadros brancos, semelhantes aos que existem nas nossas escolas, espalhados por vários locais onde os "criativos" poderão escrever as suas ideias. Ver, por exemplo, em: http://www.chilloutpoint.com/science and technology/google-office-versusfacebook-office.html. 
Segundo BROGDEN (2007: 59), foi na Grã-Bretanha que apareceu a primeira escola "primária" designada como "open plan" (área aberta), construída em 1959 em Finmere - concebida por David Medd com a colaboração de professores e de administradores. Sobre esta escola, PEARSON (1972) refere que:

Instead of offering the conventional, anonymous, box-type classroom solution, they deliberately broke up the space into a number of linked learning areas, each with a special function and character which positively invited a particular activity. Though the design aroused the criticism that architects were determining an educational pattern, all decisions were made in close collaboration with the authority's officers and teachers. Variety of educational opportunity was the keynote of the whole design, and the object was to produce a building which, in the hands of discerning teachers, contributed to the processes of learning and maturing. (PEARSON, 1972: 36).

Depois da segunda guerra mundial, com o crescimento demográfico, tornou-se necessária a construção de novas escolas, mas aquelas que foram primeiramente construídas "não reflectiam nenhuma mudança significativa em termos de direcção educacional" (HYLAND, 1980 : 18). Basicamente, tínhamos a continuação de configurações que se assemelhariam a "caixas de ovos", com salas de aula rígidas, idênticas e em forma de caixa, com um professor a trabalhar sozinho com um grupo de crianças, ensinando-os a todos ao mesmo tempo, os diferentes ritmos de aprendizagem praticamente não eram respeitados. Por exemplo, um aluno com "dificuldades" teria de fazer um esforço maior para acompanhar o resto dos colegas e um mais "avançado" teria de aprender mais lentamente do que as suas potencialidades permitiam, esperando nalgumas "matérias" pelo resto da classe.

As preocupações com redução de custos provocaram inevitavelmente uma nova abordagem no design escolar. HYLAND (1980:18) refere que no período depois de 1950 a racionalização do design de edifícios resultou na redução de espaço por aluno, mas sem que houvesse uma redução de áreas espaciais destinadas ao ensino. Inovações da época incluíam a redução na altura das salas, a utilização de áreas com dualidade de propósitos (combinando salões com 
espaços de refeição) e a redução da área total através da fusão de corredores com espaço de sala de aula.

Não existem dúvidas de que poupar dinheiro era uma questão muito importante nestes projectos em área aberta, mas não era a única. A possibilidade de implementar diferentes ideias pedagógicas e de ter espaços muito mais flexíveis e polivalentes recebeu igualmente uma atenção muito especial. Podemos dizer que estes dois aspectos deram origem às escolas de área aberta: as preocupações económicas e a influência de ideias educacionais "progressistas". Sobre este último aspecto, nunca é demais salientar que o rompimento da classe como unidade básica de ensino, o trabalho orientado por projectos, as práticas de agrupamento com diversos centros de interesse, o ensino individualizado, os métodos activos e a importância de trabalhar num meio ambiental adequado (aspecto muitíssimo enfatizado por Maria Montessori) eram ideias já defendidas pela "Educação Nova", várias décadas antes. Mais tarde, este novo conceito de área aberta na arquitectura escolar absorve estas "tendências educacionais progressistas".

Infelizmente, como referiu BRUBAKER (1998: 20), o conceito era inaceitável para alguns professores, administradores e arquitectos, criando em muitos uma forte resistência, uma vez que não queriam uma mudança tão radical nas escolas, com um conceito de espaços flexíveis, sem paredes rígidas, onde o espaço aberto poderia constantemente adaptar-se às diversas necessidades das equipas educacionais (o ensino em equipa tornava-se, especialmente nestas escolas, uma característica de extrema importância). Nos anos que se seguiram à sua abertura, a maioria das escolas de área aberta voltou aos velhos e confortáveis "programas", o espaço aberto foi dividido em salas de aula com portas que poderiam fechar-se (BRUBAKER, 1998: 20). Como escreveu BRUBAKER (1998: 20), esta situação de encerramento das áreas abertas deu-se na maioria das escolas, mas não em todas. Como é sabido, e também de acordo com este autor, algumas escolas de área aberta sobreviveram, embora apenas uma pequena percentagem destas escolas esteja "aberta", algumas têm sido construídas nos últimos anos e a construção de outras está a ser planeada. 
Várias razões poderão ser enumeradas como causas possíveis para a rejeição deste modelo arquitectónico inovador. A cultura individualista dos professores é uma delas, apontada por HARGREAVES (1988: 207), sendo muito natural a tendência de ensinar da mesma maneira que aprendemos quando fomos alunos. Afinal, mesmo sem nos apercebermos, quando somos escolarizados estamos a ser ensinados a ensinar, uma vez que a tendência será a de imitar os modelos pedagógicos que vivenciámos no passado. Tal como referia HARGREAVES em 1988, os docentes, de um modo geral, continuam a demonstrar dificuldades na realização de ensino em simultâneo num mesmo espaço:

Many attempted innovations flounder on this addiction to autonomy. Team-teaching soon becomes turn-teaching: the teachers do not work simultaneously in the same classroom, but take the whole class in turn. In 'open plan' spaces, bookcases and screens of various sorts soon appear to reconstitute the walls which guard classroom privacy. Most secondary-school teachers lack the skills needed to work together with pupils. They have a defective sense of classroom co-operation. They can co-ordinate with one another, certainly, but in matters of collaboration, the strong form of co-operation, they must be judged remedial. (HARGREAVES, 1988: 207).

Porém, como evidencia BROGDEN (2007), e como tive a oportunidade de constatar através de trabalho de campo realizado, recolhendo testemunhos de docentes que trabalharam em área aberta, é importante referir que comprovadamente os professores (os principais "actores" envolvidos neste processo) não tiveram uma formação / preparação adequada para uma pedagogia que se pretendia inovadora. BROGDEN (2007: 63) diz-nos que muito pouca ou mesmo nenhuma atenção foi dada para treinar professores para este novo paradigma. Essa opinião fundamentada de Brogden foi de novo confirmada através de e-mail que me enviou com a data de 22 de Janeiro de 2008: 
[...] teachers were not trained to work in open plan schools and many brought with them the "instruction" modes from their previous jobs. These styles did not work in the new buildings, of course, and there were problems with the voices of didactic teachers disturbing neighbouring classes. I saw open plan schools in which teachers had put up screens and tall cupboards to try to establish quiet, enclosed teaching areas.

O que acontece no Reino Unido é bastante semelhante ao que ocorreu em Portugal. Além das "falhas" (diria mesmo das responsabilidades) que os próprios professores tiveram, estando aí talvez uma das maiores contribuições para o insucesso da área aberta nas nossas escolas, Brogden, no mesmo e-mail (de 22 de Janeiro de 2008), "culpabiliza" também as lideranças, especialmente os directores (headteachers) e os responsáveis pelo planeamento. Ele próprio refere o seu caso pessoal, onde foi entrevistado para um cargo de direcção de uma nova escola de área aberta, em 1973, mas que durante a entrevista não teve qualquer pergunta sobre os "princípios" filosóficos e pedagógicos subjacentes a este tipo de edifício (the design philosophy of the building):

"I also suspect that the wrong headteacher appointments were also sometimes made so that it may be that many of the schools lacked appropriate leadership. In the UK, the headteacher was the leading figure and decided the direction the school was to take. Indeed, when I was interviewed for the headship of the new open plan school where I was to work (in 1973), I remember no questions that related to the design philosophy of the building. On appointment, I was given no explanation about the design brief. There were no courses for aspiring heads or teachers who might want to work in the new schools. There was a feeling that headship was a matter of whose turn it was, rather than any notions of personal philosophy. This was in the county of Berkshire where pioneering work was being done by the Local Education Authority in building open plan primary schools. It did not occur to the planners that they should explain what they were trying to achieve." 
Para Brogden, outro dos problemas foi o facto de se esperar que os arquitectos que trabalhavam para as "autoridades locais" construíssem escolas de área aberta, mas sem que necessariamente compreendessem o que se pretendia alcançar. Além disso, os cortes nos fundos para a construção de escolas obrigaram a criar alterações aos projectos que condicionavam negativamente a implementação de métodos "activos" de aprendizagem - Brogden refere que muitas escolas eram demasiado pequenas para que fosse feito esse tipo de trabalho. Podemos dizer que houve uma subversão das intenções originalmente propostas, inclusive dentro da própria escola, onde os professores se centravam por vezes em si mesmos, continuando mais preocupados em ensinar da forma mais "tradicional" que conheciam, quando o foco deveria estar mais na forma como os alunos deveriam de aprender. Como nos diz Brogden, quando o foco se centra mais na aprendizagem torna-se necessário que haja espaço e recursos suficientes para as crianças estudarem, debaterem, pesquisarem, fazerem perguntas e investigarem. O desenvolvimento das escolas primárias de área aberta no Reino Unido foi ainda "tomado de assalto" por considerações políticas, especialmente durante o governo de Margaret Thatcher, que reforçou noções de "escolarização limitada" (narrow schooling), com um currículo nacional com listagens dos vários conteúdos a leccionar e que deveriam ser testados. De acordo com Brogden, poucas escolas de área aberta sobreviveram a este tipo de "sabotagem":

"Another problem was that Local Education Authority architects were expected to build open plan schools but did not necessarily understand what these schools were to achieve. And cuts in the funding of school building forced many of these schools to be too small for the active learning styles they were supposed to accommodate.

The central problem might be described (simplistically) as the philosophical difference between seeing schools as places for teaching or places for learning. If the focus is on teaching, you need closed classrooms in which teachers can 
lecture their classes and the emphasis is usually on right answers. If the focus is on learning, you need enough space and resources for the children to study, discuss, enquire, research and investigate, managed by the teacher. Open plan schools were designed for the "learning" approach but often misused for the "teaching" mode so it's not surprising that many did not succeed.

[...]

In the UK, the development of open plan primary schools was overtaken by political considerations. A right-wing government under Margaret Thatcher enforced notions of narrow schooling - a national curriculum of lists of many things to be taught and tested. I think there may be only a very few schools whose confidence and clarity of purpose has enabled them to survive this "sabotage"."3

Assim, se estas escolas não tiveram as condições para trabalhar de forma apropriada, não podemos afirmar que é impossível que elas funcionem extremamente bem com a inovação pretendida. De facto, alguns professores acreditam que as vantagens trazidas pelo design em área aberta compensariam os riscos e as dificuldades que poderiam surgir. Neville Bennett 4 , através de comunicação com a data de 30 de Abril de 2008, via e-mail, referiu-me que "chegaram à conclusão que alguns designs eram melhores do que outros e que poderiam funcionar bem desde que os professores tivessem a percepção das possibilidades do uso do espaço e estivessem bem organizados"5. Resposta no mesmo sentido foi-me dada por Mike Brogden quando o questionei sobre a

3 Excerto do e-mail enviado por Mike Brogden, em 22 de Janeiro de 2008.

$4 \quad$ Neville Bennett estudou em profundidade estas matérias, tendo dirigido um importante estudo sobre escolas de área aberta, realizado entre os anos de 1975-1978 (BENNETT et al., 1980). O trabalho de Bennett tem especial relevância uma vez que é realizado já após alguma contestação ao "modelo" de escolas de área aberta.

5 As palavras que o professor Bennett usou no e-mail foram as seguintes: "We came to the conclusion that some designs were better than others and that they could work well provided that teachers were aware of the possibilities of space use and were well organised." 
viabilidade das escolas de área aberta. Todavia, Brogden destaca ainda a importância da escolha de equipas docentes apropriadas, com filosofias educacionais e pessoais que lhes permitam compreender os princípios inerentes às escolas de área aberta:

"Could the open plan schools "work" if the necessary conditions for success were given?

Yes and some did, but the necessary conditions include choosing staff with the appropriate personal and educational philosophies who understood the principles upon which these schools were built. Time was not given to this, partly because the rise in the birth rate necessitated a rapid building and staffing programme."6

Mesmo num ambiente favorecido pelas tecnologias do século $X X I \quad 0$ conceito poderá funcionar realmente bem. $\mathrm{Na}$ "Escola do Futuro"7, tive a oportunidade de "viver" a experiência de colocar alguns destes princípios pedagógicos em prática, tais como: o ensino em equipa; o uso de pequenos agrupamentos de alunos para trabalhar em diferentes conteúdos ao mesmo tempo; a individualização das aprendizagens, de acordo com as potencialidades e capacidades de cada aluno. No inquérito que realizei após o "evento" ("aula do futuro"), 95\% dos alunos prefere este tipo de ensino (quantas vezes não nos esquecemos de perguntar aos nossos estudantes o que eles realmente pensam...) e $100 \%$, ou seja todos, consideram que tem mais vantagens e que é mais facilitador da aprendizagem.

$6 \quad$ Excerto do e-mail enviado por Mike Brogden, em 22 de Janeiro de 2008.

7 A "Escola do Futuro" a que me refiro encontra-se dentro do Museu das Comunicações, na cidade de Lisboa. No dia 16 de Janeiro de 2008, juntamente com alguns alunos do Instituto Piaget, que estavam a realizar a licenciatura em ensino, e com a participação de alunos de uma escola básica do $1^{\circ}$ ciclo, estive a realizar uma manhã de actividades lectivas "inspiradas" no "espírito" das escolas de área aberta. Os resultados foram extremamente favoráveis, o que serviu para me demonstrar que este tipo de abordagem pedagógica tem não somente uma grande viabilidade de realização, mas também enormes potencialidades para facilitar o processo de ensino/aprendizagem, especialmente com Tecnologias de Informação e Comunicação. 
Uma publicação/compilação sobre edifícios educacionais exemplares, seleccionados por um júri internacional, reconhecendo respostas "inovadoras" ("forward-looking responses") para um ambiente de ensino e aprendizagem em mudança, abre o seu segundo capítulo ("The School of the Future") exactamente com uma escola de área aberta na Finlândia (ORGANISATION FOR ECONOMIC CO-OPERATION AND DEVELOPMENT, 2001: 40). Em Portugal, a Escola da Ponte, uma das nossas instituições de ensino básico mais inovadoras, ainda respeita o seu design original em open space. Muito provavelmente, o futuro do design escolar será inspirado em experiências arquitectónicas do passado.

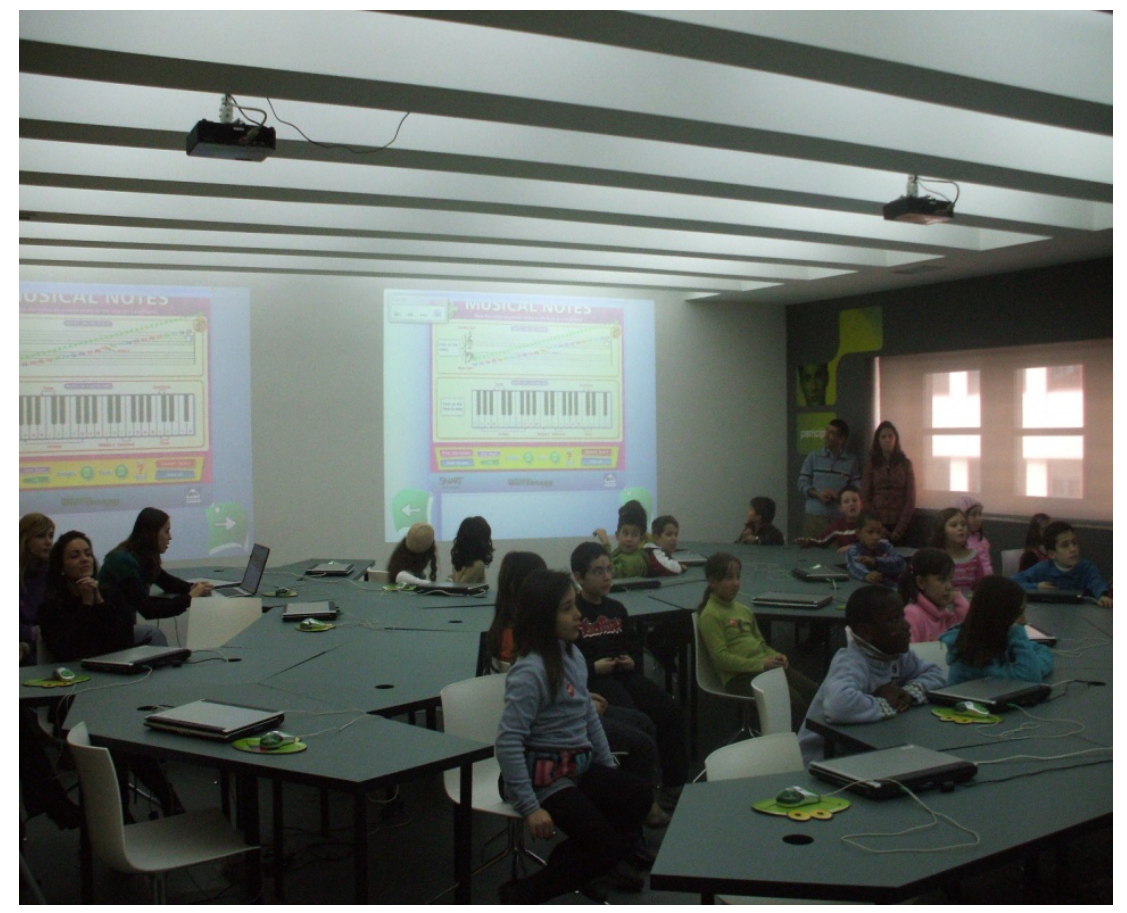

Figura 2 - "Escola do Futuro" (dentro do Museu das Comunicações)

O Projecto Regional do Mediterrâneo, da Organização para a Cooperação e Desenvolvimento Económico (OCDE), teve um papel fundamental no desenvolvimento da arquitectura escolar em Portugal. Através desse "plano" foi criado um grupo com arquitectos, engenheiros e consultores pedagógicos que trabalharam com a orientação de um arquitecto inglês com o nome de Guy Oddie. Esse grupo foi integrado num projecto da Organização para a Cooperação e 
Desenvolvimento Económico designado por DEEB (Development and Economy in Educational Building), no qual fizeram parte equipas de outros países, como Espanha, Jugoslávia, Grécia e Turquia (AFONSO [coord.], 1984: 88). Como resultado desta colaboração, foi construída uma escola piloto em Mem Martins (próximo de Lisboa), tendo sido inaugurada em 1966.

A equipa de trabalho constituída realizou pesquisa em busca de outras concepções pedagógicas e de novas relações entre o espaço escolar e as actividades de aprendizagem. A reforma dos próprios programas escolares também resultou da colaboração com os técnicos de outros países (FELGUEIRAS, 2007: 64). Embora a escola piloto não fosse em área aberta apresentava, no entanto, algumas características relativamente inovadoras para a época, a mais evidente era a disponibilidade de uma maior área destinada para o ensino do que aconteceria no caso das escolas do "Plano dos Centenários" (projecto tipo que dispúnhamos anteriormente, desde os anos 1940). Além disso, surge nesta escola piloto um espaço polivalente que poderia ser utilizado não só como cantina, mas que permitiria de igual modo a sua utilização como biblioteca, espaço de exposições, adequando-se à realização de projecções, de conferências, servindo ainda para outras actividades - como a dança, o teatro, a música, a educação física e o desporto. A escola foi projectada com quatro salas de aula articuladas à volta de um pátio central, havendo por parte dos arquitectos e pedagogos uma preocupação com a flexibilidade espacial que anteriormente não seria tão evidente. Surgem dentro das salas de aula da escola piloto novas zonas de trabalho para a realização de actividades práticas, facilitando a utilização de água com lavatórios à disposição (practical work bay with sink - ver figura 3). Convém recordar que nas antigas escolas do "Plano dos Centenários", a realização de trabalhos com água, como aconteceria no caso da pintura ou com a modelação de barro, era extremamente dificultada, uma vez que, não existindo água canalizada dentro da sala, os alunos eram obrigados a deslocar-se muitas vezes à casa de banho, perdendo mais tempo para concretizar este tipo de tarefas. 


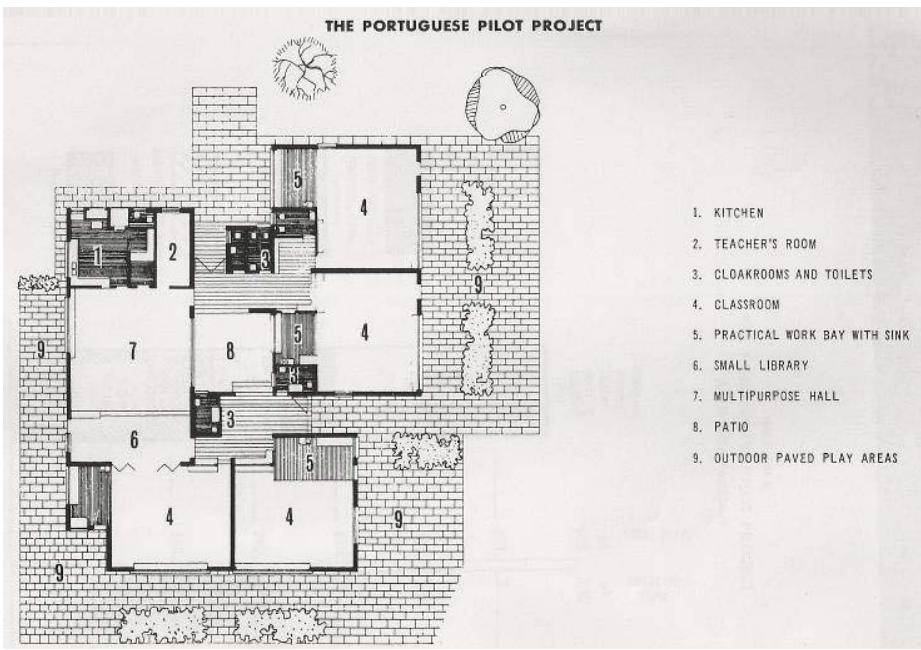

Figura 3 - Planta da escola piloto de Mem Martins8

FELGUEIRAS (2007: 64) refere que as equipas técnicas que trabalharam nas construções escolares tiveram a oportunidade de visitar ou de entrar em contacto com peritos e escolas estrangeiras, tal afirmação é reforçada com o testemunho dos autores do relatório da visita efectuada a Inglaterra (MINISTÉRIO DAS OBRAS PÚBLICAS / D. G. C. E. / G. E. P., 1971), neste documento é apontada como finalidade: "ver algumas escolas primárias inglesas e contactar com entidades ligadas às mesmas". Claramente influenciados por "novas" concepções pedagógicas, os técnicos que trabalhavam nas construções escolares procuraram novas relações entre o espaço escolar, a criança e as actividades de ensino/aprendizagem. Tendo em conta que havia na altura uma muito forte tendência para a construção de escolas de área aberta, particularmente em Inglaterra, uma vez que o Plowden report (PLOWDEN et al., 1967) contribui para as tornar ainda mais populares, Maria do Carmo Matos, uma das arquitectas que trabalhou no projecto da escola piloto de Mem Martins, seguiu esta tendência e com uma nova equipa concebeu um projecto de escolas de área aberta que é conhecido nos nossos dias como "P3". Este projecto surgiu com a pretensão de organizar a escola em espaços orgânicos abertos, possibilitando o trabalho conjunto dos professores e uma mais fácil circulação das crianças. O mobiliário seria renovado, com novos elementos e com a substituição das carteiras por

8 Planta retirada de ORGANISATION FOR ECONOMIC CO-OPERATION AND DEVELOPMENT (1968: 29). 
mesas e cadeiras, sendo mais apto para o trabalho individual (nalgumas situações com ensino individualizado) ou em grupos (FELGUEIRAS, 2007: 64).
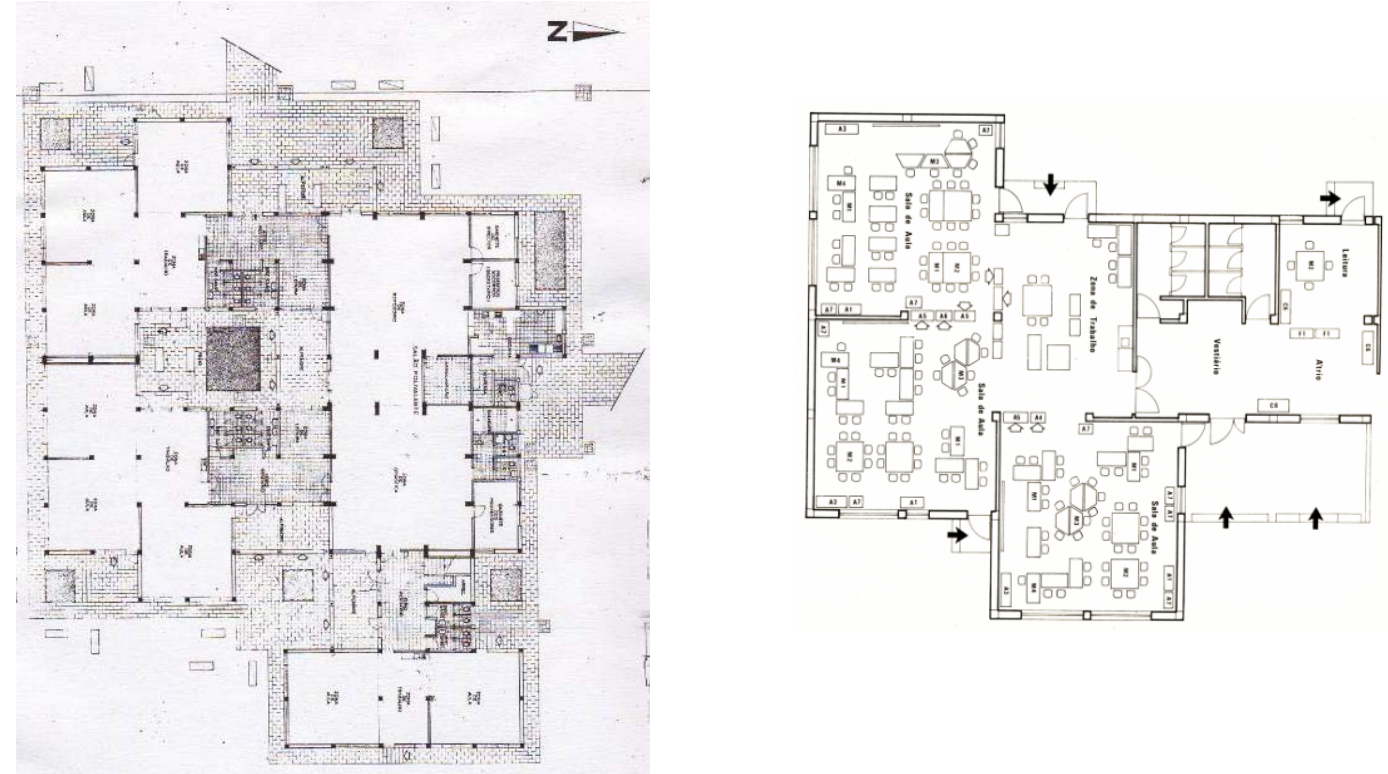

Figura 4 - Planta do rés-do-chão da primeira "P3" construída9

De acordo com AFONSO [coord.] (1984: 100 e 101), os critérios que se tomaram em consideração na elaboração do projecto foram: o desajustamento de outros projectos disponíveis naquela altura com os "novos" objectivos pedagógicos; a necessidade urgente de construir escolas primárias por todo o país (em pouco tempo e numa quantidade considerável); a dificuldade que havia na época de apreciar e executar projectos caso a caso e a falta de recursos económicos. Estas razões motivaram a elaboração do projecto normalizado de escolas de área aberta "P3", havendo, segundo AFONSO [coord.] (1984: 100), dois tipos de objectivos prioritários, nomeadamente, os pedagógicos e os construtivos:

9 Do lado direito podemos ver com maior detalhe uma das possibilidades de arranjo espacial para um núcleo em área aberta (com três "salas de aula"). De salientar que na mesma escola existiam também núcleos de "duas salas" (ver planta do lado esquerdo, em baixo). 
“a) Pedagógicos - criação de uma escola que tornasse possível o ensino em grupo (desde grupos muito pequenos a muito grandes) e a diversificação das actividades de aprendizagem dos alunos.

b) Construtivos - criação de um projecto com um mínimo de variáveis a nível de elementos de construção que possibilitasse uma maior variedade de soluções de lotação e de adaptação aos terrenos."

(AFONSO [coord.], 1984: 100).

Surge então um projecto normalizado que pode adaptar-se, sofrendo ligeiras alterações, não só às condições de terreno, mas também às necessidades da população, ao contrário do projecto tipo, onde exactamente a mesma estrutura era construída em diferentes locais. O projecto normalizado "P3" destacava-se pelas suas características de flexibilidade, mas ao mesmo tempo era repetitivo, o que facilitava os processos de construção, de adaptação e até de ampliação. Como é salientado em AFONSO [coord.] (1984: 100 e 101), procurava-se ainda que:

“- A partir de diferentes blocos se pudessem obter associações variadas tendo em vista o número de salas, as características do terreno e a orientação dos edifícios de modo a evitar a monotonia e a rigidez de um projecto-tipo.

- Uma solução construtiva modulada, que tivesse em vista a racionalização da construção e a possibilidade de utilização da prefabricação.

- Possibilitasse ampliações futuras, sem alteração da estrutura existente."

(AFONSO [coord.], 1984: 100 e 101).

Como resultado dos estudos realizados a propósito da elaboração do projecto "P3", Maria do Carmo Matos também desenhou outras escolas de área aberta, que resultaram de solicitações que esta arquitecta teve por parte de algumas autarquias (BEJA et al., 2007: 56). Esses projectos não tiveram a denominação de "P3", todavia, resultaram de facto nas primeiras escolas de área aberta que viríamos a ter em Portugal. 


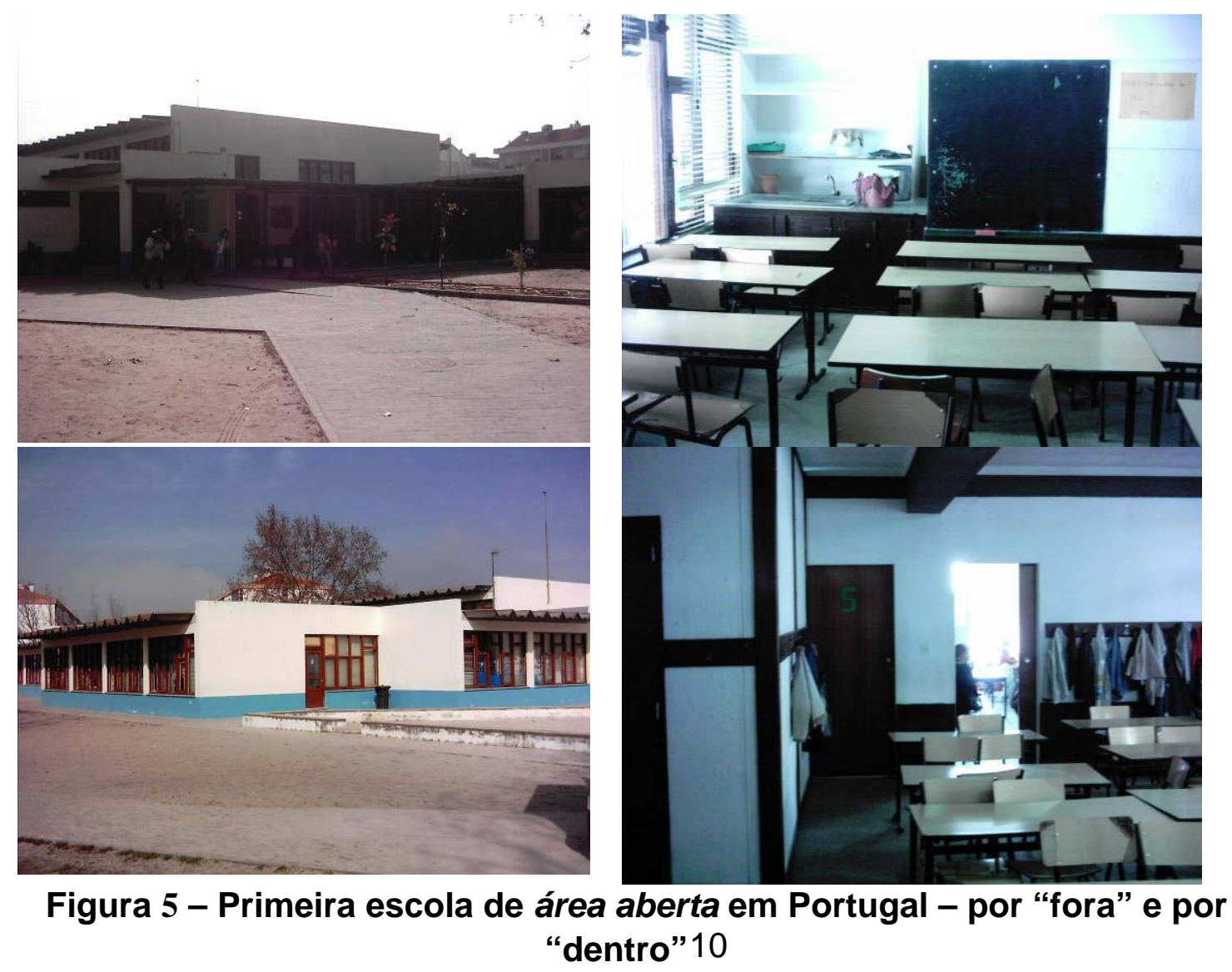

As escolas de área aberta do projecto "P3" foram construídas em Portugal praticamente por todo o país. Em Julho de 1985 já tínhamos construído 371 edifícios desse tipo, de acordo com mapa elaborado pela Direcção-Geral do Ensino Básico (DGEB/DSPRI, 1985). A variedade que o projecto permitia, com núcleos que poderiam ter diferentes tamanhos e uma construção modular muito adaptável, teve como resultado uma grande diversidade de opções construtivas,

10 Esta escola, que resultou do trabalho desenvolvido pela arquitecta Maria do Carmo Matos, entrou em funcionamento no dia 2 de Novembro de 1973 (M.E.C./D.G.E.E., sem data) e localiza-se na Moita. A captação das fotografias aconteceu no dia 1 de Fevereiro de 2007, na sequência de trabalho de campo efectuado por mim nesta zona. Nessa altura funcionava como escola básica do $1^{\circ}$ ciclo e jardim-de-infância. De salientar que já tinha há muito tempo abandonado o sistema organizativo em área aberta. Como se pode observar nas fotografias do lado direito, do interior do edifício, temos uma "zona de trabalho" com acesso a lavatório que foi "fechada" (antes pertencia a um núcleo em área aberta) e foi transformada numa sala de aula "tradicional". Fui informado que neste espaço funcionam as aulas de inglês de "enriquecimento curricular". Pelo que pude observar, esta "zona de trabalho" passou a ser mais uma "sala de aula" e o trabalho de expressão artística e plástica que aqui poderia ter lugar teve de sacrificar as suas actividades, deixando de poder utilizar este espaço a tempo inteiro (provavelmente, teremos aqui, como em muitas outras situações, mais um "empobrecimento curricular" na área específica das expressões). 
uma vez que poderíamos adicionar ou remover módulos - poderei até acrescentar que, embora tenha visitado um número considerável destas escolas, nunca encontrei duas "P3" exactamente iguais em termos de configuração espacial.

Porém, e como já tive a oportunidade de referir anteriormente, o design destes edifícios foi rejeitado e provocou resistência às "novas" abordagens de ensino que o espaço em área aberta permitia. Houve queixas em relação ao nível de ruído e além disso os professores não tiveram uma formação adequada que Ihes permitisse trabalhar neste "novo" ambiente (DSPRI, DIRECÇÃO DE SERVIÇOS DO ENSINO PRIMÁRIO, 1983). A área aberta foi imposta a muitos docentes, uma vez que foram ensinar para estas escolas não por opção pedagógica, mas por outro tipo de conveniências (a colocação de professores era feita a partir de concurso que inicialmente não diferenciava uma escola de área aberta de uma outra qualquer). Os professores estavam habituados a trabalhar de uma forma bastante "tradicional", trabalhando sozinhos, com apenas um professor em cada sala de aula, desconheciam por isso, de um modo geral, as particularidades exigidas numa escola pensada para uma prática pedagógica diferente, onde as metodologias activas estariam mais em evidência do que as expositivas/transmissivas, onde o ensino em equipa requeria um outro tipo de planificação, procurando-se uma individualização do processo de ensino/aprendizagem.

Esta mudança de paradigma, descrita de forma sucinta no parágrafo anterior, não foi bem recebida e vários protestos surgiram contra este tipo de escolas. Muito rapidamente paredes foram construídas dentro dos núcleos e os espaços em área aberta foram sucessivamente fechados. As práticas pedagógicas não mudaram com a arquitectura, muitos professores transformaram os núcleos de área aberta em salas de aulas "tradicionais", semelhantes àquelas onde eles próprios estudaram (onde foram "formatados" e "enculturados" como alunos e professores) e onde poderiam ensinar de uma forma em que se sentiriam mais confortáveis.

Felizmente, nem todos os professores em Portugal rejeitaram as escolas concebidas originalmente em área aberta, alguns até solicitaram um edifício com 
essas características, como foi o caso daqueles que trabalharam na Escola da Ponte:

"A Escola da Ponte é uma escola de área aberta construída por vontade dos professores, onde não foram erguidos muros nos lugares em que os arquitectos derrubaram as paredes.

A arquitectura também desempenha um importante papel na concretização dos objectivos do projecto. [...]

Nesta escola não há salas de aula e não há aulas. Um espaço pode, no princípio de um dia de trabalho, acolher o trabalho de grupo, pode servir a expressão dramática, a meio da manhã, e pode receber, no fim do dia, as crianças que vão participar no debate. Num mesmo dia, o polivalente pode ser um espaço de cantina, de assembleia, de expressão dramática, de educação físico-motora..."

(PACHECO, 2004: 95).

Esta vontade de trabalhar na Escola da Ponte em área aberta foi confirmada por várias fontes, através de entrevistas que tive a oportunidade de fazer a José Pacheco (um dos principais mentores do projecto, pertencente ao grupo de docentes que "criou" esta escola), através de artigos que ele mesmo escreveu (PACHECO, 1998: 164; PACHECO, 2004: 95) ou ainda através do testemunho de outros professores que trabalharam naquela instituição de ensino. Podemos ainda comprovar a importância da arquitectura no projecto educativo da Escola da Ponte visionando o vídeo com o título "Fazer a Ponte" (PACHECO et al., 2000), onde é referido que:

"Um dos aspectos fundamentais tem a ver com a própria estrutura do espaço e permite que os alunos se desloquem para o seu trabalho diário sem depender do professor."11

11 Retirado do vídeo "Fazer a Ponte" (PACHECO et al., 2000). 
A Escola da Ponte, juntamente com a Escola de Monserrate, em Viana do Castelo, foram os dois estabelecimentos de ensino portugueses nomeados em 2006 no "Guia de Experiências Inovadoras"12, guia esse que consiste numa recolha de dez casos, de vários países, de êxito no combate ao insucesso13 e ao abandono escolar (PINTO, 2006). Mesmo antes desta nomeação, era bastante evidente que a Escola da Ponte era um caso muito particular de inovação educacional em Portugal (ver, por exemplo, CANÁRIO, 2004). Uma das principais diferenças que conduziu ao "sucesso" neste caso foi o facto de a equipa docente14 ter arriscado com uma enorme adesão ao processo de inovação que se pretendia instituir. Em vez de "lutar" contra a arquitectura, os professores decidiram usá-la como parte do seu projecto educativo.

12 Segundo PINTO (2006), este guia surge como resultado de um trabalho desenvolvido desde 2005 pelos participantes no projecto YOUTRAIN - New Challenges on Youth Training in the Knowledge Society. No grupo de trabalho estão representados centros de investigação de vários países (Portugal, Áustria, Espanha, Reino Unido e Roménia).

13 No relatório apresentado pela Comissão de Avaliação Externa do Projecto Fazer a Ponte, ver RAPOSO; BIDARRA \& FIGUEIRA (2003: 41), podia ler-se o seguinte: "[...] exceptuando os resultados verificados com a parte da prova de aferição de Língua Portuguesa de 2000 incidente em dois dos três itens da produção escrita, os valores atingidos pelos alunos da EBI das Aves/S. Tomé de Negrelos [designação atribuída à Escola da Ponte] são, na maioria dos itens das provas de Língua Portuguesa e de Matemática, superiores naqueles alunos comparativamente às médias à escala regional e à escala nacional."

14 Embora a equipe docente possa ter sido prejudicada por elementos perturbadores como a rotatividade (saída e entrada/colocação de alguns professores), não tenho dúvidas, com base em várias visitas que pude efectuar à Escola da Ponte, que de um modo geral nesta instituição as pessoas se regiam por uma série de princípios fundamentais para a realização de um ensino em equipa que pudesse perdurar ao longo do tempo. CONDERMAN; BRESNAHAN \& PEDERSEN (2009: 3 e seguintes) apresentam-nos alguns dos pré-requisitos para a concretização de ensino em equipa: paridade, trabalho de parceria com espírito de igualdade; respeito mútuo; objectivos específicos mútuos; partilha da "contabilidade" dos resultados (shared accountability for outcomes); partilha de recursos (CONDERMAN; BRESNAHAN \& PEDERSEN, 2009: 3-5). Estes autores consideram ainda que o "clima da escola" (onde poderá ou não existir uma cultura colaborativa, por exemplo), o apoio dos pais e encarregados de educação, o apoio da própria administração (providenciando formação adequada), as perspectivas dos estudantes e as características pessoais de todos os elementos devem ser ainda alguns dos factores adicionais a ter em consideração para que o ensino em equipa tenha sucesso (CONDERMAN; BRESNAHAN \& PEDERSEN, 2009: 5-7). É por isso que não é possível "exportar" ou copiar os princípios de uma escola que funcione bem em área aberta, uma vez que o contexto não será o mesmo. 


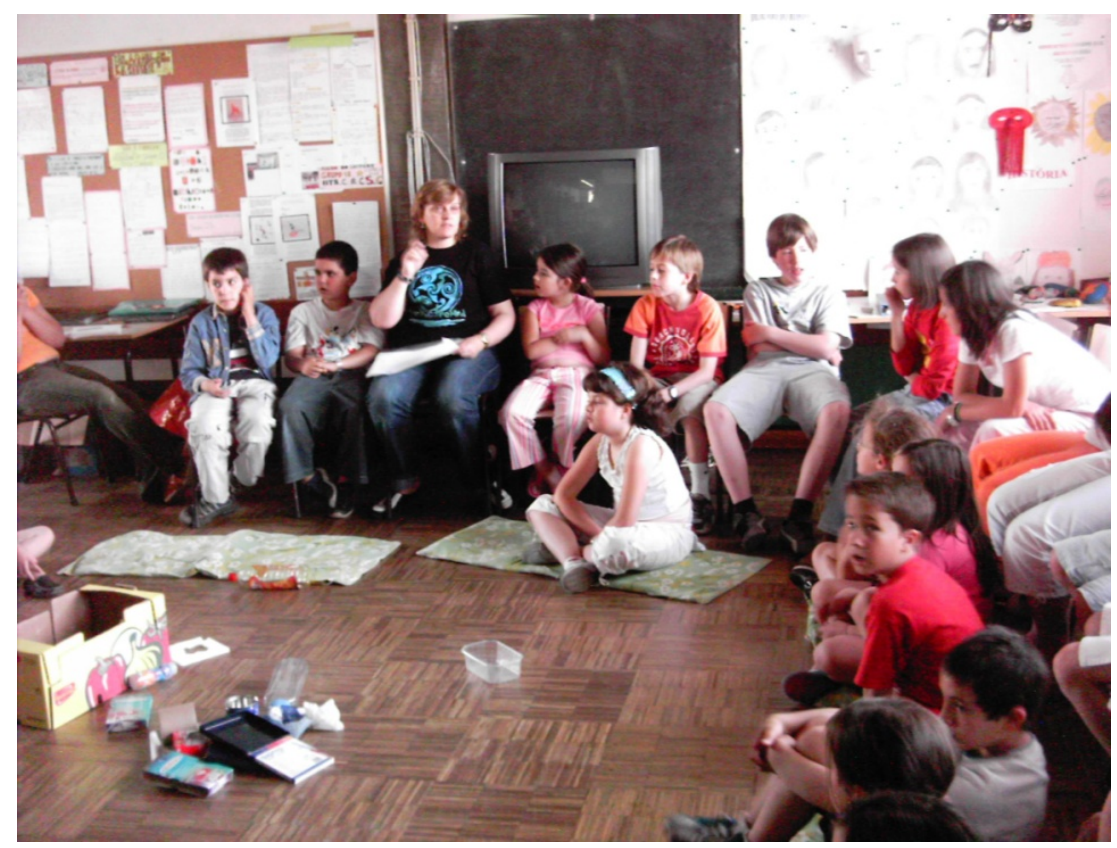

Figura 6 - Uma outra forma de aprender dentro de um núcleo da Escola da Ponte

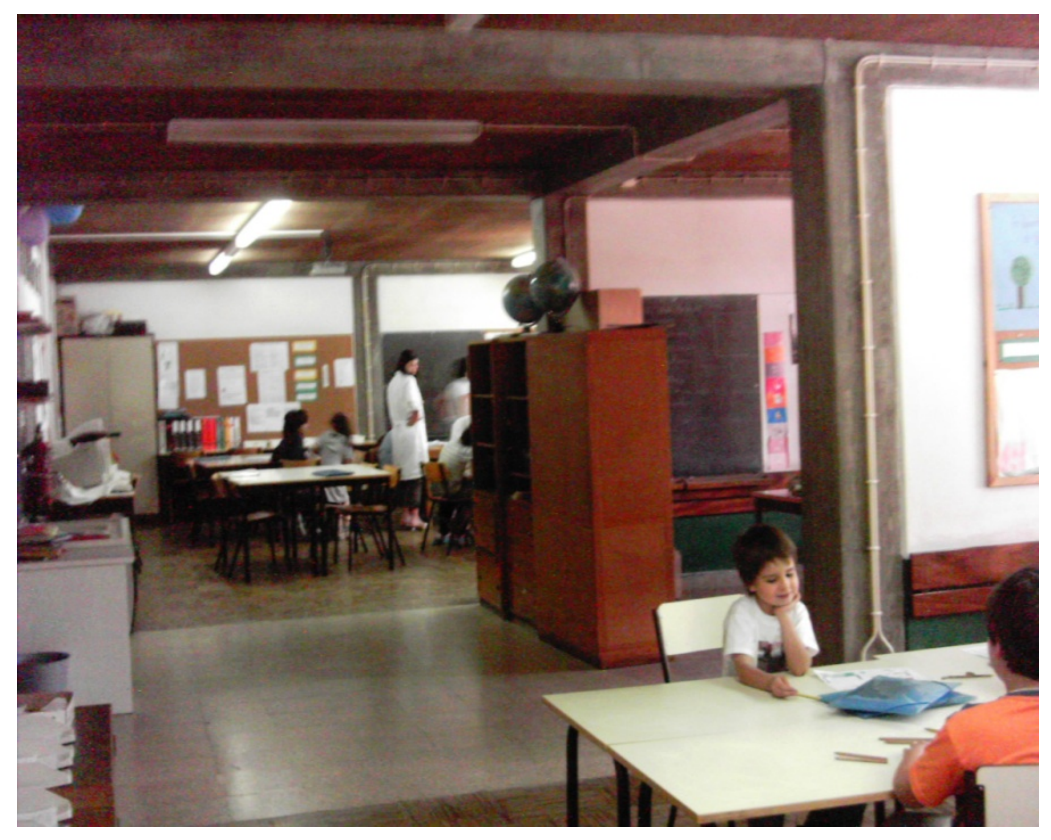

Figura 7 - Um dos núcleos da Escola da Ponte (ainda em área aberta)

Como se pode observar na figura 7, o edifício "P3" da Escola da Ponte continua a funcionar em área aberta. Embora se possa dizer que esta escola básica tem "uma cultura própria, uma ideologia específica", como salientaram 
RAPOSO; BIDARRA \& FIGUEIRA (2003: 16), teremos sempre de reconhecer que parte do mérito desta instituição é devido à inovação arquitectónica trazida pelo projecto "P3". De acordo com RAPOSO; BIDARRA \& FIGUEIRA (2003: 7), para além da organização dos espaços na Escola da Ponte se revelar adequada ao modelo pedagógico que é desenvolvido, este modelo apresenta algumas analogias com aquele que esteve na base da construção das escolas do projecto normalizado "P3":

"É um facto que, genericamente, os espaços proporcionados pelas escolas tipo P3 privilegiam a comunicação, libertam a criança da rigidez de espaços e mobiliários tradicionais, encorajando, fundamentalmente, as relações entre os alunos e entre estes e os educadores, mobilizando, igualmente, os professores para o trabalho em equipa. Esta configuração do espaço facilita a adaptação da organização escolar às diferenças individuais e à contínua aquisição de conhecimentos; permite os reagrupamentos funcionais de alunos; estimula nas crianças a multiplicação dos contactos pessoais e, por conseguinte, a sociabilização; facilita diferentes tipos de didáctica e pedagogia, favorecendo, igualmente, todas as formas de trabalho dos alunos (individual, em grupo e actividades livres)."

(RAPOSO; BIDARRA \& FIGUEIRA, 2003: 7 e 8).

Como referem estes autores (2003: 8), o espaço poderá ter limitações ou potencialidades de acordo com as concepções e práticas pedagógicas que se desenvolvam. No caso da Escola da Ponte, o projecto educativo e o próprio edifício "interpelam-se" reciprocamente, esta configuração do espaço físico em área aberta possibilitou condições para o desenvolvimento de um trabalho participativo e democrático (RAPOSO; BIDARRA \& FIGUEIRA, 2003: 8). Quando surgiram as escolas de área aberta ("P3") tivemos inovação no parque escolar (do naquela altura denominado Ensino Primário). Porém, estes edifícios "P3" nem sempre estiveram ajustados com a cultura de ensino e as práticas pedagógicas dominantes (RAPOSO; BIDARRA \& FIGUEIRA, 2003: 7). A "cultura própria" da 
Escola da Ponte e também o facto de procurar desenvolver uma pedagogia "alternativa" possibilitaram a manutenção da inovação e, consequentemente, não permitiram o "fecho" dos espaços em área aberta.

É certo que são principalmente as pessoas que se envolvem no trabalho de uma escola que a fazem evoluir e transformar-se. A participação e a aceitação da inovação por parte da comunidade educativa permitem reacções menos adversas a determinadas mudanças, especialmente se houver apoio por parte de pais e encarregados de educação e uma compreensão e um desejo de adquirir novos métodos de trabalho por parte de alunos, funcionários e professores. Foram as pessoas que fizeram a diferença no caso da Escola da Ponte, foi graças a elas que se desenvolveu um projecto educativo singular, foram elas, especialmente os professores, que mantiveram e deram "vida" aos espaços em área aberta. Como adverte PERRENOUD (2004: 89), o surgimento de práticas inovadoras não garante só por si a sua adopção por parte de outros professores, é conveniente que o processo de mudança se faça com todas as pessoas (e não contra elas). Seguindo este raciocínio, podemos afirmar que o insucesso de muitas escolas de área aberta também deverá ser atribuído àqueles que nelas trabalharam. Para MALEHORN (1978: 14), a verdadeira essência de uma "educação aberta"15 continua a residir nas atitudes básicas do professor, na sensibilidade para ver as crianças como pessoas e na receptividade à mudança:

15 O autor utiliza no texto original o termo openness que, embora seja muitas vezes associado a open area ou open space, tem, no entanto, um sentido mais abrangente, relacionando-se com o que MALEHORN (1978) e TRAUB et al. (1976) definem como "Educação Aberta" (Open Education). Segundo TRAUB et al. (1976: 1), a "Educação Aberta" pode ser definida como aquela que maximiza as escolhas dos estudantes em todas as dimensões escolares. Esta definição parece ser consistente com a essência do movimento humanista, assim como com a área da psicologia que relaciona o desenvolvimento de ambientes livres de restrições que impedem o indivíduo de atingir plenamente o seu potencial (TRAUB et al., 1976: 1). Recentemente, com a grande influência de "novos" meios tecnológicos, tem surgido várias publicações que nos obrigam a redefinir o conceito de "Educação Aberta", e até mesmo a descobrir novas variáveis no processo de ensino/aprendizagem, vejam-se por exemplo os trabalhos de RUDOLPH \& FRANKEL (2009) e de BONK (2009). BONK não só nos mostra como as aspirações da "Educação Aberta" são agora mais facilmente atingíveis (BONK, 2009: 46), mas principalmente procura evidenciar as formas como a Web technology está a revolucionar o mundo da Educação. De qualquer modo, o que importa aqui destacar é que o grau de receptividade à mudança condiciona, mais ou menos favoravelmente, a introdução de novos paradigmas educacionais. 
"Opening space in the traditional building or creating a brand new open school produces open learning only if the professionals involved in the decision making insure that the form of their classrooms follows the functions that are to be conducted inside the structure. An open space which is well planned and well supervised offers a measure of mobility that open learning certainly can use. Open space serves the child's frequent need to chose where he wants to be, and it accommodates the variety of learning centers and media that must be readily accessible to the student. In the traditional classroom the child is much more likely to be restricted to the single self-contained classroom and to a common set of materials and media, but the open area permits the learner to sample a wider selection of locations and learning experiences."

(MALEHORN, 1978: 15).

Como referem RAPOSO; BIDARRA \& FIGUEIRA (2003: 46), na Escola da Ponte não estamos perante uma teoria construída somente na prática, mas antes disso, confrontamo-nos com uma prática baseada em princípios metodológicos colaborativos, democráticos, reflectidos, sistematicamente testados e revistos, que se baseiam, entre outros, no pensamento de Dewey, Freinet e Paulo Freire e nos Movimentos da Escola Moderna e da Escola Nova. Os ideais da "Educação Aberta" (Open Education), além de revitalizarem certas práticas e movimentos pedagógicos, trouxeram-nos também alguma inovação, tendo sido mais tarde as suas principais ideias "aproveitadas" pelos professores da Escola da Ponte. Como é salientado por TRAUB et al. (1976: 1 e 2), foram vários os factores que influenciaram o desenvolvimento da "Educação Aberta" (Open Education), beneficiando o aparecimento de modelos pedagógicos "alternativos". Um dos factores foi o crescimento do envolvimento de pais e encarregados de educação nas actividades e assuntos relacionados com a escola, determinando, ou procurando, outro tipo de experiência escolar que os seus educandos deviam vivenciar (TRAUB et al., 1976: 2).

Porém, segundo TRAUB et al. (1976: 1), a mais significante influência no desenvolvimento da "Educação Aberta" na América do Norte terá sido 
provavelmente a divulgação de relatórios sobre programas que operavam em escolas da Grã-Bretanha (como o caso do já referido Plowden report), onde os professores dessas escolas procuravam um ensino individualizado com os estudantes e davam ênfase a procedimentos de ensino mais flexíveis. Além disso, e ainda de acordo com TRAUB et al. (1976: 2), surge também inovação na forma como os programas escolares poderiam ser organizados, com novas técnicas de ensino e novos papeis a desempenhar pelos professores. Entre estas mudanças, procurava-se acentuar o ensino individualizado (e a tecnologia adequada a ele); havia um crescimento da ênfase na não graduação, com programas de progresso contínuo; desenvolvia-se o conceito de ensino em equipa, onde outros profissionais podiam inclusivamente apoiar o trabalho dos professores:

"[...] the concept of team teaching as a replacement for the idea that teachers must work individually and in isolation; and the use of paraprofessionals to support the work of the teacher. These changes have helped transform the elementary school classroom from a basically homogeneous learning situation to an environment characterized by heterogeneous activities and roles."

(TRAUB et al., 1976: 2).

Finalmente, um outro importante factor que influenciou o desenvolvimento e a expansão das ideias da "Educação Aberta" terá sido o crescimento da percepção sobre a importância da qualidade dos ambientes físicos 16 no processo de ensino/aprendizagem, tendo outras partes da sociedade, como por exemplo os meios laborais de empresas e de escritórios (especialmente em open space), contribuído para essa mudança:

"Much of this awareness has stemmed from changes that have been taking place in other parts of society. For the past two decades, architects have been redesigning the spaces in which individuals work, utilizing increased knowledge

$16 \quad$ Nunca é de mais relembrar que a qualidade dos ambientes físicos também tem conexões com as preocupações económicas, pensemos por exemplo na possibilidade de poupar dinheiro com a construção de menos paredes interiores em espaços de área aberta. 
about materials, structural design, and the psychology of work. The concept of office landscaping has become popular, with its emphasis on spaciousness and flexibility. Educators have come to believe that these considerations are no less important for groups of students and teachers crowded into relatively small schoolrooms than they are for office and factory workers. Thus, schools have been built without internal walls to create space that can readily accommodate many different activities. These schools make it easier to group and regroup students, and provide a sense of openness."

(TRAUB et al., 1976: 2).

Já vimos que no caso da Escola da Ponte o projecto arquitectónico (edifício "P3", em área aberta) desempenhou um papel fundamental no desenvolvimento do projecto educativo. Para além das vantagens que os espaços em área aberta trouxeram para a aprendizagem dos alunos, também a equipa docente teve benefícios com o processo de inovação que se tentou implementar. Uma das conclusões do estudo levado a cabo por TRAUB et al. (1976: 55 e 56) é que as variáveis de programa e de arquitectura estão fortemente relacionadas com as atitudes dos professores. Segundo estes autores, os docentes que trabalham em escolas de área aberta têm atitudes mais positivas e existe maior interacção entre eles do que aqueles que trabalham em escolas mais "fechadas":

"[...] the evidence indicated that teachers in open-area schools interact with other teachers and with the principle more often than do their counterparts in closed and mixed-area schools. These results are not unexpected since the increased visibility provided by open architecture encourages more frequent interpersonal contact."

(TRAUB et al., 1976: 56).

Talvez os benefícios que a área aberta pode trazer nas atitudes dos professores expliquem um dos principais pontos fortes apontados no relatório elaborado por RAPOSO; BIDARRA \& FIGUEIRA (2003: 44) sobre a Escola da 
Ponte, nomeadamente, a "existência de um conjunto de docentes altamente motivados e empenhados no processo de acompanhamento dos alunos na respectiva aprendizagem". Todavia, se fizermos uma leitura sobre as escolas de área aberta mais atenta e abrangente, com as devidas ligações ao conceito de "Educação Aberta", não teremos apenas a associação da área aberta com um dos pontos fortes da Escola da Ponte, mas sim com todos os outros indicados por RAPOSO; BIDARRA \& FIGUEIRA (2003: 44 e 45). No relatório da Comissão de Avaliação Externa do Projecto Fazer a Ponte são ainda estabelecidos os seguintes pontos fortes:

"- A filosofia subjacente ao Projecto "Fazer a Ponte", caracterizada por princípios de desenvolvimento da autonomia e da cooperação entre os alunos, com a finalidade de educar para e na cidadania e de efectivo envolvimento de todos os intervenientes na acção educativa (pais, professores e alunos);

- A realização de uma integração curricular, desenvolvida de acordo com os princípios de um ensino e uma aprendizagem cooperativos;

[…]

- A presença de um acentuado espírito de corpo e de identificação com o Projecto por parte de docentes e de alunos;

- A preocupação da Escola em constituir-se como escola inclusiva, em termos sociais, culturais e de intervenção junto de alunos com necessidades educativas especiais;

- A diversidade de modos de actividade (trabalho individual, em pequeno grupo, participação em actividades colectivas, ensino mútuo e ensino directo) pedagógica;

- A adequada articulação entre objectivos e actividades correspondentes às diversas áreas curriculares;

- A ligação entre a escola e a família, implicando a participação activa desta na aprendizagem dos alunos; 
- A qualidade dos materiais de aprendizagem, nomeadamente do equipamento informático17 (hardware e software)."

(RAPOSO; BIDARRA \& FIGUEIRA, 2003: 44 e 45).

As vantagens trazidas pela arquitectura das escolas de área aberta e pelas práticas pedagógicas a elas associadas, tal como aconteceria em qualquer outro tipo de organização onde se ensina, poderão ser anuladas pela não adesão dos indivíduos envolvidos. O contrário disso aconteceu na Escola da Ponte, e esse é um mérito que terá de ser reconhecido aos docentes que aí ensinaram em equipa e em área aberta, não só aderiram ao processo de mudança, aceitando novas formas de trabalhar, como também acabaram por "reinventar" a inovação. É certo que o processo de implementação de uma escola de área aberta trará sempre riscos ao longo do tempo. Porém, também em qualquer outro estabelecimento de ensino a introdução de um novo elemento, como por exemplo uma forma de ensinar "alternativa", arriscar-se-á a falhar caso não haja adesão por parte das pessoas envolvidas, sendo obrigatório que estas partilhem interesses e valores comuns (ou seja, que se identifiquem com a mesma "cultura"/subcultura escolar).

É preciso agir sobre as pessoas, ou que elas interajam entre si, não bastará fornecer aos espaços escolares simplesmente os edifícios ou os materiais e as estruturas físicas adequadas. Existe a necessidade de uma actuação em simultâneo sobre os indivíduos e as estruturas, talvez até esta deva ser antecipada sobre os primeiros, especialmente professores, para que tenham tempo de fazer formação e para que seja conseguida uma estratégia de mudança que os associe e englobe. Mesmo com o empenho de todos os docentes, com uma planificação adequada (fundamental para um ensino em equipa), com espaços e recursos que reúnam as condições necessárias, poderão haver

17 Embora na altura do aparecimento das escolas de área aberta o equipamento informático não estivesse disponível, tal como acontece nos nossos dias, recordaria aqui, como é referido por MALEHORN, que o conceito de área aberta permitiria "acomodar" variedade de media e de centros de aprendizagem que deveriam estar prontamente acessíveis para os estudantes (MALEHORN, 1978: 15). Em diversas circunstâncias, conceitos que hoje nos podem parecer extremamente "modernos" já foram muitas vezes "imaginados" e até discutidos em profundidade por gerações anteriores, pensemos, por exemplo, em ideias específicas como as "teias de aprendizagem" propostas por Ivan ILLICH (1976: 123 e seguintes), e que hoje são facilitadas pelo uso da Internet, ou em casos mais gerais como as influências trazidas pelos ideais da "Educação Nova". 
retrocessos. Sabemos agora que não teria sido a configuração espacial em área aberta que "falhou"18 no projecto "P3", mas foram essencialmente outras situações que levaram ao "fecho" das áreas abertas. Para além de não haver uma adequada formação de professores, existiu falta de estabilidade das equipas docentes e, em muitos casos, houve excesso de alunos por núcleo. Porém, o que falhou principalmente nas escolas de área aberta foi o desajuste entre as concepções pedagógicas (bem diferentes das que pude encontrar na Escola da Ponte) e o programa arquitectónico.

\section{REFERÊNCIAS}

AFONSO, José [coord.] (1984). Escolas primárias. Lisboa: Centro Nacional de Cultura (documento policopiado).

18 Já vimos que nem todas as escolas de área aberta "falharam" em Portugal, embora seja importante salientar que tenham havido alguns problemas arquitectónicos nos edifícios. Nalgumas zonas do país e nalgumas escolas surgiram problemas com a temperatura e com os níveis de ruído. 
BEJA, Filomena et al. (2007). Muitos anos de escolas. Volume III. Edifícios para o ensino infantil e primário. Da escola piloto à área aberta. Casos especiais. Lisboa: Ministério da Educação - Secretaria-Geral, Divisão de Documentação e do Património Cultural, Núcleo de Arquivo Técnico de Construções Escolares (documento policopiado).

BENNETT, Neville et al. (1980). Open plan schools: teaching, curriculum, design. Windsor: NFER Publishing Company for the Schools Council.

BONK, Curtis (2009). The world is open: how Web technology is revolutionizing education. San Francisco: Jossey-Bass.

BROGDEN, Mike (2007). "Plowden and Primary School Buildings: a story of innovation without change". FORUM: for promoting 3-19 comprehensive education. 49 (1), 55-66.

BRUBAKER, C. William (1998). Planning and designing schools. New York: McGraw-Hill.

CANÁRIO, Rui (2004). "Uma inovação apesar das reformas". Em: CANÁRIO, Rui; MATOS, Filomena \& TRINDADE, Rui [Orgs.]. Escola da Ponte. Defender a Escola Pública. Porto: Profedições, 31-41.

CONDERMAN, Greg; BRESNAHAN, Val \& PEDERSEN, Theresa (2009). Purposeful co-teaching: real cases and effective strategies. Thousand Oaks, California: Corwin Press.

DGEB/DSPRI (1985). Escolas tipo P3. Mapa de Portugal continental encontrado no espólio da Professora Helena Mendes, com o número de escolas tipo P3 por distrito e o número de alunos e de professores que frequentavam essas escolas em Julho de 1985.

DSPRI, DIRECÇÃO DE SERVIÇOS DO ENSINO PRIMÁRIO (1983). Resultados do inquérito distribuído às professoras de escolas de área aberta - tipo P3 - do ensino primário no $3^{\circ}$ período de 81/82. Lisboa: Direcção-Geral do Ensino Básico/Ministério da Educação.

FELGUEIRAS, Margarida (2007). "A arquitectura da escola primária em Portugal nos séculos XIX e XX". Em: GÓMEZ FERNÁNDEZ, Juan; ESPIGADO TOCINO, Gloria \& BEAS MIRANDA, Miguel (Eds.). La escuela y sus 
escenarios. Actas de los IX Encuentros de Primavera en El Puerto. El

Puerto de Santa María: Concejalía de Cultura del Ayuntamiento de El Puerto de Santa María, 37-65.

HAMILTON, David (1976). A Case Study of a New Scottish Open Plan School. Edinburgh: The Scottish Council for Research in Education.

HARGREAVES, David (1988). The challenge for the comprehensive school: culture, curriculum and community. London: Routledge and Kegan Paul.

HYLAND, Terry (1980). "Philosophical and historical background". Em: BENNETT, Neville et al. Open plan schools: teaching, curriculum, design. Windsor: NFER Publishing Company for the Schools Council, 11-27.

ILLICH, Ivan (1976). Sociedade sem escolas ( $3^{\mathrm{a}}$ ed.). Petrópolis: Editora Vozes. (Edição original: 1971).

M.E.C.ID.G.E.E. (sem data). Escolas do ensino primário a funcionar em edifícios $P 3$. Documento policopiado encontrado no espólio da professora Maria Helena Mendes.

MALEHORN, Hal (1978). Open to change. Santa Monica, California: Goodyear Publishing Company.

MINISTÉRIO DAS OBRAS PÚBLICAS / D. G. C. E. / G. E. P. (1971). Missão a Inglaterra 22/11/70 a 3/12/70 - relatório. Lisboa: Gabinete de Estudos e Planeamento / Direcção-Geral das Construções Escolares / Ministério das Obras Públicas.

ORGANISATION FOR ECONOMIC CO-OPERATION AND DEVELOPMENT (1968). Development and economy in educational building (report on the OECD project). Paris: OECD Publications.

ORGANISATION FOR ECONOMIC CO-OPERATION AND DEVELOPMENT (2001). Designs for learning: 55 Exemplary Educational Facilities. Paris: OECD Publications.

PACHECO, José (1998). "Fazer a Ponte". Em: MOREIRA, M. ${ }^{a}$ Margarida et al. Experiências inovadoras no ensino: inovação pedagógica. Lisboa: Instituto de Inovação Educacional, 159-179. 
PACHECO, José (2004). "Uma escola sem muros". Em: CANÁRIO, Rui; MATOS, Filomena \& TRINDADE, Rui [orgs.]. Escola da Ponte. Defender a escola pública. Porto: Profedições, 95-122.

PACHECO, José et al. (2000). Fazer a Ponte. [Videotape - 8 min.]. Lisboa: Instituto de Inovação Educacional/Escola Básica n. ${ }^{\circ} 1$ da Ponte - Vila das Aves.

PEARSON, Eric (1972). Trends in school design. New York: Citation Press.

PERRENOUD, Philippe (2004). Aprender a negociar a mudança em educação Novas estratégias de inovação ( $2^{\mathrm{a}}$ ed.). Porto: Edições ASA.

PINTO, Teresa (2006). "Guia de experiências inovadoras - exemplos de êxito no combate ao insucesso escolar". BICA, newsletter da CNOTINFOR, n. ${ }^{\circ} 15-$ Julho e Agosto de 2006. Consultado no dia 2010-12-27, em WWW: http://bica.cnotinfor.pt/2006/guia-de-experiencias-inovadoras-exemplos-deexito-no-combate-ao-insucesso-escolar/

PLOWDEN, Bridget et al. (1967). Children and their primary schools. A report of the central advisory council for education (England). London: Her Majesty's Stationery Office.

RAPOSO, Nicolau; BIDARRA, M. ${ }^{a}$ da Graça \& FIGUEIRA, Ana (2003). Relatório apresentado a S. Ex. ${ }^{a}$ a Secretária de Estado da Educação ([pela] Comissão de Avaliação Externa do Projecto Fazer a Ponte). Consultado em: http://www.escoladaponte.com.pt/documen/CAEPonte.pdf [data da consulta: 2010-12-27].

RUDOLPH, Thomas \& FRANKEL, James (2009). YouTube in music education. New York: Hal Leonard.

TRAUB, Ross et al. (1976). Openness in schools. An evaluation study. Toronto, Ontario: OISE (The Ontario Institute for Studies in Education). 